\title{
Uma nova espécie de Senna Mill. (Leguminosae - Caesalpinoideae) DO BRASIL
}

\author{
Andréa Onofre de Araujo ${ }^{1,2}$ \& Vinicius Castro Souza ${ }^{1}$
}

\begin{abstract}
Resumo
(Uma nova espécie de Senna Mill. (Leguminosae - Caesalpinoideae) do Brasil) Senna biglandularis, uma nova espécie pertencente à série Laxiflorae, seção Chamaefistula, proveniente do estado de Tocantins (Brasil) é descrita e ilustrada, incluindo dados de hábitat e fenologia. Dentre os caracteres diferenciais da nova espécie estão a presença de dois nectários extraflorais no pedicelo e pétalas glabras em ambas as faces. Além disso, é apresentada uma chave de identificação de todas as espécies pertencentes à série Laxiflorae.
\end{abstract}

Palavras-chave: Chamaefistula, Laxiflorae, cerrado, Tocantins.

\section{Abstract}

(A new species of Senna Mill. (Leguminosae - Caesalpinoideae) from Brazil) Senna biglandularis, a new species belonging to series Laxiflorae, section Chamaefistula, from Tocantins state (Brazil) is described and illustrated, including comments on habitat and phenology data. The main diagnostic characters of the new species are its pedicel with two extrafloral nectaries and its petals, glabrous on both sides. An identification key for all species included in series Laxiflorae is also presented.

Key words: Chamaefistula, Laxiflorae, cerrado, Tocantins.

\section{INTRODUÇÃOO}

Senna inclui cerca de 350 espécies, $80 \%$ ocorrendo no continente americano, sendo aproximadamente 60 espécies encontradas no Brasil (Irwin \& Barneby 1982; Randell \& Barlow 1998).

O gênero é incluído na subtribo Cassiinae, juntamente com Cassia e Chamaecrista. Estudos filogenéticos apontaram que Senna é monofilético, porém o relacionamento dentro da subtribo não está completamente resolvido, sendo que este gênero pode aparecer como irmão de Cassia, como apontado por Bruneau et al. (2001) e por Marazzi et al. (2006), ou como grupo irmão de Chamaecrista, como apontado por Herendeen et al. (2003).

Irwin \& Barneby (1982) reconheceram seis seções dentro de Senna: Astroites, Chamaefistula, Paradictyon, Peiranisia,
Psilorhegma e Senna, sendo que Chamaefistula seria a maior delas, com aproximadamente 140 espécies. Além disso, esses autores reconheceram 35 séries dentro do gênero. Marazzi et al. (2006) apontaram que apenas a seção Psilorhegma é monofilética. No entanto várias séries reconhecidas por Irwin \& Barneby (1982) apareceram como monofiléticas, entre elas Aphyllae, Deserticolae, Isandrae, Bacillares, Basiglandulosae, Galeottianae e Laxiflorae, sendo as quatro últimas pertencentes à seção Chamaefistula (Marazzi et al. 2006).

A nova espécie de Senna aqui descrita, pertencente à série Laxiflorae, foi observada durante a realização da monografia desse gênero para a Flora dos estados de Goiás e Tocantins, Coleção Rizzo (V.C.Souza et al., dados não publicados).

Artigo recebido em 08/2006. Aceito para publicação em 03/2007.

'Universidade de São Paulo, Escola Superior de Agricultura "Luiz de Queiroz”, Av. Pádua Dias 11, 13418-900, Piracicaba, SP, Brasil.

22Autor para correspondência: aonofrearaujo@yahoo.com.br 


\section{Chave de identificação das espécies da seção Chamaefistula, série Laxiflorae}

1. Nectário extrafloral ausente apenas no par proximal de folíolos

S. cana (Nees \& Mart.) H.S.Irwin \& Barneby

1'. Nectário extrafloral presente entre todos os pares de folíolos.

2. Estilete 5-9,5 mm; legumes $0,9-1 \mathrm{~cm}$ de largura; sementes transversas no fruto, com aréola grande $( \pm 3 \times 1 \mathrm{~mm})$

S. lechriosperma H.S. Irwin \& Barneby

2'. Estilete 3,5-7 mm; legumes 3-5 mm de largura; sementes verticais no fruto, com aréola pequena $(1-1,5 \times 0,4-0,8 \mathrm{~mm})$.

3. Ápice dos folíolos triangular, deltado ou obtuso, comumente mucronulado ou caudadoacuminado; pedicelo com 1 nectário em forma de chifre; todas as sépalas dorsalmente pubescentes S. velutina (Vogel) H.S.Irwin \& Barneby

3'. Ápice dos folíolos fortemente obtuso, arredondado, abertamente emarginado ou agudo, às vezes mucronulado; pedicelo com 1-2 nectários fauciformes, fusiforme- elipsóides ou ovóides; sépalas internas dorsalmente glabras.

4. Folhas com face adaxial pubescente, às vezes esparsamente pubescente; pedicelo sempre com 2 nectários extraflorais; pétalas glabras em ambas as faces

S. biglandularis A.O.Araujo \& V.C.Souza

4'. Folhas com face adaxial lustrosa e glabra; pedicelo com 1(-2) nectário(s) extrafloral(is); pétalas pubescentes dorsalmente

S. appendiculata (Vogel) Wiersema

Senna biglandularis A.O.Araujo \& V.C. Souza, sp. nov. Tipo: BRASIL. TOCANTINS: Ponte Alta do Tocantins, estrada para Monte do Carmo, beira de estrada, $10^{\circ} 39^{\prime} 35,5^{\prime \prime} \mathrm{S}$, $47^{\circ} 42^{\prime} 56,8^{\prime \prime W}$, 18.VII.2000, fl. fr., V.C. Souza, J.P. Souza \& G.O. Romão 24196 (holótipo: ESA; isótipos: $\mathrm{K}, \mathrm{NY}, \mathrm{RB}, \mathrm{SPF}, \mathrm{UFG})$.

Fig. 1

Affinis Sennae appendiculatae (Vogel) Wiersema nectariis extra-floralibus inter omnes pares foliolorum et corolla zygomorpha sed folia supra pubescentia, 2 nectariis pedicello et petalis utrinque glabris differt.

Subarbustos a arbustos, 1-2,5 m alt.; ramos pubescentes, com tricomas muito curtos. Pecíolo 1-2 cm compr.; raque 2,9-8 cm compr.; estípulas 6-7 mm compr., linearlanceoladas; nectários extraflorais entre todos os pares de folíolos, oblongo-ovóides, ápice arredondado, sésseis; folíolos (2-)4-6 pares, $1,4-6,3 \times 0,9-3 \mathrm{~cm}$, ovais, oblongos ou elípticos, ápice emarginado, arredondado ou agudo, às vezes mucronulado, base cordada, simétrica ou assimétrica, face adaxial pubescente, às vezes esparsamente, abaxial pubescente.
Inflorescência racemo; brácteas caducas, não vistas; pedicelo 1,6-3 cm compr., com 2 nectários extraflorais fauciformes na base; sépala maior 1,5-2 cm compr.; corola zigomorfa, pétala maior 2,8-3,7 cm compr., glabra em ambas as faces; androceu composto por 3 estaminódios, 4 estames adaxiais com anteras retas e com bico, 3 estames abaxiais, com o central um pouco menor que os laterais, com anteras $1-1,9 \mathrm{~cm}$ compr., encurvadas e com bico; estilete $2,5-2,8 \mathrm{~cm}$ compr. Fruto maduro linear, quadrangular, $10,8-19 \times 0,3-0,5 \mathrm{~cm}$, pubescente quando imaturo. Sementes oblongas, 3-4×3 mm.

Distribuição e hábitat: coletada somente no estado de Tocantins em área de cerrado, afloramento rochoso e beira de estrada.

Fenologia: coletado com flores em junho e julho, com frutos em julho.

A espécie pertence à seção Chamaefistula, série Laxiflorae (Irwin \& Barneby 1982), a qual é apontada por Marazzi et al. (2006) como uma série monofilética (BS $=100 \%)$ e grupo irmão da série monotípica Confertae. Ainda segundo esses autores, o clado 


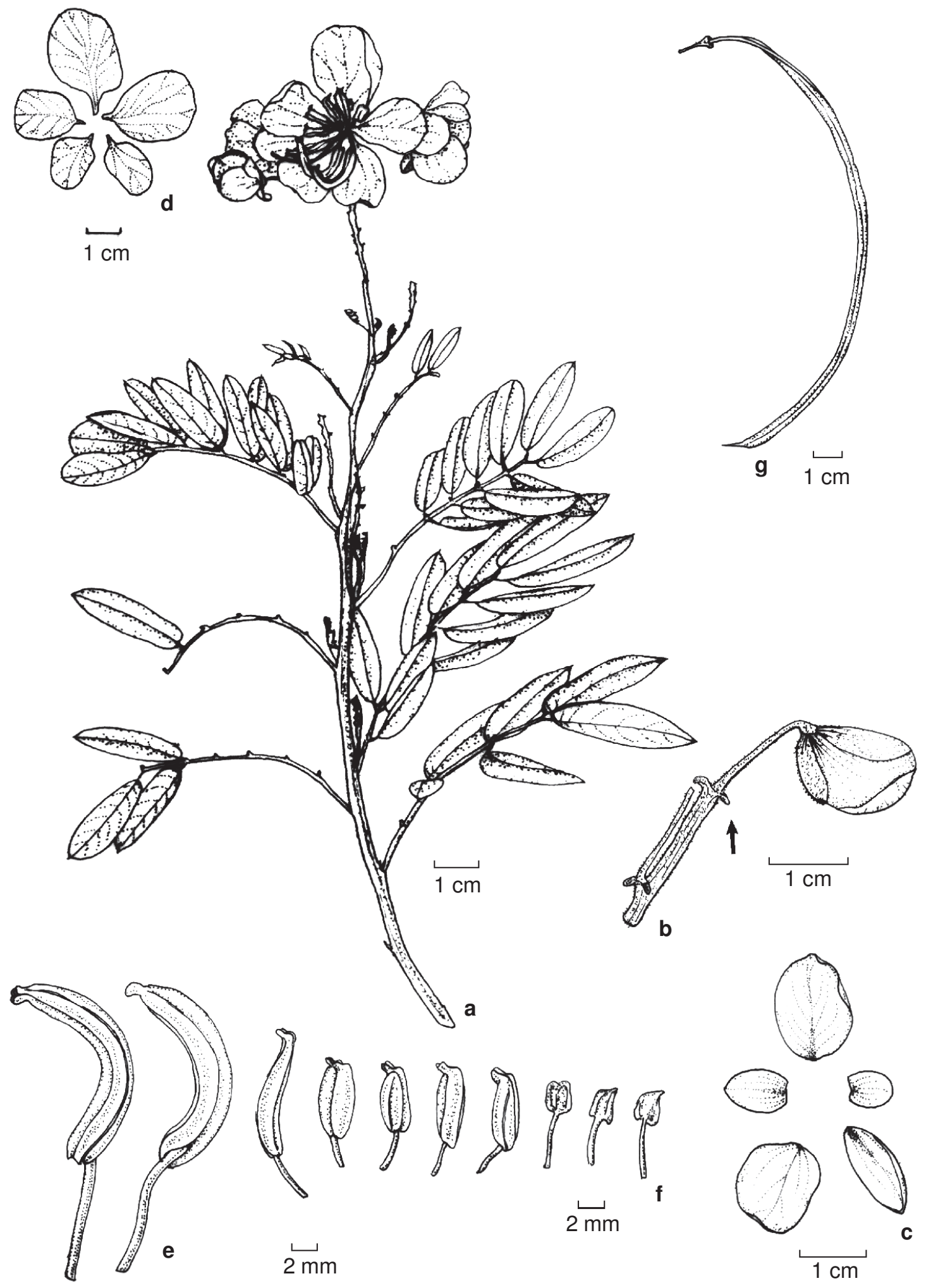

Figura 1 - Senna biglandularis A.O.Araujo \& V.C.Souza - a. hábito; b. botão floral com nectários extraflorais na base do pedicelo indicados por seta; c. sépalas; d. pétalas; e. estames; f. estaminódios; g. fruto. (a Souza 24419; b, d-f Rizzo 9910; c Souza 24196; g Souza 24253) 
formado por essas duas séries teria como sinapomorfias a presença de nectários extraflorais na base do pedicelo e a presença de nectários similares nas folhas.

Essa nova espécie assemelha-se a Senna appendiculata (pertencente à mesma série), mas diferencia-se facilmente por apresentar folhas com face adaxial pubescente, às vezes esparsamente pubescente, sempre 2 nectários extraflorais fauciformes no pedicelo e pétalas glabras em ambas as faces. S. appendiculata apresenta folhas com face adaxial lustrosa e glabra, 1(-2) nectário(s) extrafloral(is) fusiforme- elipsóides ou ovóides no pedicelo e pétalas pubescentes dorsalmente. Além disso, S. appendiculata ocorre apenas no litoral (do sul da Bahia ao sudoeste do Rio de Janeiro) e $S$. biglandularis no interior do Brasil.

Parátipos: BRASIL. TOCANTINS: Novo Jardim, estrada para Barreiras, $11^{\circ} 47^{\prime} 42^{\prime \prime} \mathrm{S}, 46^{\circ} 23^{\prime} 04^{\prime \prime} \mathrm{W}$, 21.VII.2000, bot., fl. e fr., V. C. Souza et al. 24419 (ESA); estrada para Placas, rod. TO-280, 1149'17"S, $46^{\circ} 21^{\prime} 44^{\prime \prime}$ W, 20.VII.2000, fl. e fr., V. C. Souza et al. 24253 (ESA, UB); Ponte Alta do Tocantins, $20 \mathrm{~km}$ de Ponte Alta do Norte, 13.VI.1974, bot. e fl., J. A. Rizzo 9910 (ESA, UFG).

\section{Agradecimentos}

Os autores agradecem à FAPESP pela bolsa concedida (processo 00/01258-1); ao Dr. Gwilym Peter Lewis pelas sugestões; ao Dr. Tarciso Filgueiras pelo auxílio na diagnose em latim; e a Ana Paula Savassi Coutinho pela leitura do manuscrito.

\section{REFERÊNCIAS BIBLIOGRÁFICAS}

Bruneau, A.; Forest, F.; Herendeen, P. S.; Klitgaard, B. B. \& Lewis, G. P. 2001. Phylogenetic relationships in the Caesalpinioideae (Leguminosae) as inferred from chloroplast trnL intron sequences. Systematic Botany 26: 487-514.

Irwin, H. S. \& Barneby, R. C. 1982. The American Cassiinae. Memoirs of the New York Botanical Garden 35(1-2): 1-918.

Marazzi, B.; Endress, P. K.; Queiroz, L. P. \& Conti, E. 2006. Phylogenetic relationships within Senna (Leguminosae, Cassiinae) based on three chloroplast DNA regions: patterns in the evolution of floral symmetry and extrafloral nectaries. American Journal of Botany 93(2): 288-303.

Randell, B. R. \& Barlow, B. A. 1998. Senna. Flora of Australia 12: 89-138. 